\title{
Ética e sustentabilidade nas Relações Públicas
}

\section{Alípio Casali}

- Pós-Doutor pela Universidade de Paris

- Doutor e Mestre em Educação pela Pontifícia Universidade Católica de São Paulo (PUC-SP)

- Filósofo

- Professor Titular da Pós-Graduação da PUC-SP

- Autor de diversos artigos e livros na área da educação e afins e conferencista internacional

- Foi Vice-Reitor de Planejamento e Administração da PUC-SP

- Foi membro do Conselho Municipal de Educação de São Paulo

- Foi Secretário Municipal dos Negócios Extraordinários de São Paulo

- Foi membro do Conselho Administrativo de empresas públicas da Cidade de São Paulo (Prodam, Anhembi, Teatro Municipal)

- Atuou como consultor do Banco Mundial e do PNUD

- É consultor na área de Responsabilidade Social de empresas, especificamente em torno a projetos de elaboração de Código de Ética Empresarial e de Gestão da Ética

- a.casali@uol.com.br 


\section{Resumo}

O presente ensaio aborda o tema da Ética nas Relações Públicas e seu principal desafio posto hoje, a saber, o da sustentabilidade dos empreendimentos. Considera-se como principal condição dessa sustentabilidade a realização universal dos direitos de todos os públicos implicados na ação institucional. Para isso, trabalha-se com a noção ampliada de Relações Públicas e de "partes interessadas". São abordados alguns dos desafios a uma conduta ética adequada nas Relações Públicas, entre eles o conflito entre transparência e sigilo.

PALAVRAS-CHAVE: RELAÇÕES PÚBLICAS • ÉTICA • SUSTENTABILIDADE.

\section{Abstract}

This essay addresses the theme Ethics in Public Relations from the aspect of the current major challenge, i.e., the sustainability of enterprises. Universal achievement of the rights of all of the publics involved in such institutional actions is considered to be the main condition for this sustainability. A broadened concept of Public Relations and Stakeholders is assumed. Some of the challenges for proper ethical conduct in Public Relations are addressed, among them the conflict between transparency and secrecy.

KEYWORDS: PUBLIC RELATIONS • ETHICS • SUSTAINABILITY

\section{Resumen}

Se aborda el tema de la Ética en las Relaciones Públicas desde la perspectiva del principal reto actual: el de la sostenibilidad de los emprendimientos. Se considera como principal condición para esta sostenibilidad la realización universal de los derechos de todos los públicos implicados en tal acción institucional. Para ello, se utiliza una noción ampliada de Relaciones Públicas y de "Partes Interesadas". Se abordan algunos de los desafíos para una conducta ética adecuada en las Relaciones Públicas; entre ellos, el conflicto entre transparencia y sigilo.

PALABRAS CLAVE: RELACIONES PÚBLICAS • ÉTICA • SOSTENIBILIDAD 


\section{Ética e sustentabilidade nas Relações Públicas}

C hego a este tema com um olhar externo. Venho do meio público para observar as instituições em suas relações públicas com os portadores de interesses e direitos universais. Trago um olhar habituado ao crivo da crítica filosófica. A intenção é que essa crítica se exerça em dois âmbitos complementares: o epistemológico e o ético. Epistemológico, porque se trata de buscar referências de validação de conceitos e conhecimentos que ultrapassem maximamente o âmbito dos interesses institucionais. Ético, porque se trata de ir além do âmbito particular da moral (também institucional e cultural particular). A expectativa é que essa alteridade crítica possa gerar um diálogo interdisciplinar e produzir alguma fecundação ao tema.

Durante o largo tempo em que o conceito de Relações Públicas esteve associado quase exclusivamente às organizações de mercado, foi inevitável que ele tivesse sofrido uma grave distorção em seu alcance. Refiro-me à redução do conceito de público a uma pequena parcela de seu universo: a dos consumidores e clientes. Neste ensaio volto a considerar o conceito de Relações Públicas dentro desse mesmo campo restrito das instituições do mercado, porém agora com uma perspectiva mais crítica em sua abordagem.

Vale lembrar, de partida, que o vocábulo público deriva de populicus, que é o adjetivo de populus (povo). Ainda que o significado de povo seja sempre, em alguma medida, limitado por particularidades culturais como língua, costumes, nacionalidade, território, história comum, entre outras, ele já apresenta um alcance muito mais amplo que o do âmbito institucional, e é isso que importa superar aqui, já que nos colocamos com a pretensão de perspectiva epistemológica e ética críticas.

Pretendo abordar o tema da Ética nas Relações Públicas de um ponto de vista do principal desafio posto hoje, a saber, o da sustentabilidade dos empreendimentos. Considerarei como principal condição dessa sustentabilidade a realização universal dos direitos de todos os públicos implicados na sua ação institucional.

\section{A ampliação do conceito de Relações Públicas e de "partes interessadas"}

O que vem se passando nas instituições de mercado, nas últimas décadas, com a súbita entrada em pauta do conceito de responsabilidade ambiental, social e cultural, tem sido sinal de que um novo movimento iniciou-se para se recuperarem algumas referências críticas para a ação empresarial que nunca poderiam ter sido perdidas. Estamos apenas começando uma história, que poderá ou não ser bem sucedida, de integração das dinâmicas do mercado com as dinâmicas sociais e culturais, e de reencontro da trilha da sustentabilidade. Esse movimento mostra-se já na adoção, suficientemente consensual (ao menos formalmente), de que toda organização deve compreender-se como parte da rede de relações que estabelece com todas as suas "partes interessadas". Essa expressão entre aspas, sabemos, vem de um conceito formulado pelo mercado norteamericano, e resultou de um certo trocadilho com o conceito de stockholders (acionis- 
tas): muitas empresas viviam, até os anos 80, exclusivamente focadas nos interesses de seus acionistas, o que se foi mostrando um viés injusto e insustentável. Num mercado altamente competitivo, movimentando-se num meio social e cultural caracterizado por intensos processos de informação e comunicação (tornados possíveis e impulsionados por tecnologias cada vez mais sofisticadas), o interlocutor das organizações obrigatoriamente ampliou-se, universalizando-se consideravelmente. Na sociedade de massas contemporânea, clientes, consumidores, fornecedores, comunidades, mídia, a sociedade em geral, passaram a apresentar-se como sujeitos cada vez mais ativos e conscientes de serem parte do negócio, com um poder crescente de determinação sobre a viabilidade dos negócios (poder de boicote e de promoção). Daí o jogo semântico do novo conceito: esses sujeitos em seu conjunto foram chamados de stakeholders por serem os que efetivamente sustentam os empreendimentos nos quais estão direta ou indiretamente implicados (stake é uma estaca ou coluna de sustentação).

Mas a tradução portuguesa desse conceito (stakeholders $=$ partes interessadas) não foi a mais criteriosa, e por isso obriga-nos a estabelecer uma importante distinção entre interesses e direitos. O vocábulo interesse, ainda que contenha uma semântica rica (inter-esse [latim] = estar dentro ou no meio de uma situação ou processo), teve seu alcance convencionalmente limitado aos aspectos econômicos e de prestígio social (interesse, no mercado, é algo como uma expectativa de se auferirem resultados econômicos e, para isso, ter prestígio é uma mediação indispensável). O problema é que não há, no mercado, dispositivos suficientes para regular nem o montante de resultados (bens e riquezas) possíveis de serem acumulados, nem o poder de influência (prestígio) social e cultural, sendo ambos de alcance ilimitado. E a conseqüência de tal infinitude é, evidentemente, o desequilíbrio social e a insustentabilidade. Já temos ameaçadores exemplos dessa exorbitância: se colocarmos num prato de balança as quatro maiores fortunas pessoais do mundo, no outro prato precisaríamos colocar, para equilibrar, quase 50 nações com mais de 600 milhões de pessoas.

Assim sendo, é indispensável registrar que nem todo interesse corresponde a um direito. Porque a afirmação do direito implica a sua acessibilidade efetiva (sua efetividade [de facto] e não apenas sua afirmação formal [de iure]). E não é possível garantir a todos o direito de acesso aos bens necessários à realização de uma vida digna (fundamento primeiro e último de todos os direitos) sem alguma regulação desse acesso. Isso se dá porque, por um lado, os bens naturais são limitados e finitos e, por outro lado, o modo social de produção de riquezas predominante nas sociedades ocidentais é o do relacionamento contratual entre sujeitos econômicos em posição socialmente assimétrica (uns são proprietários de meios de produção; outros, não sendo proprietários, têm apenas sua força de trabalho para dispor e alugar em troca de salários que não correspondem, em última instância, ao montante de valor que seu trabalho efetivamente agregou às mercadorias produzidas). Donde emerge como indispensável o Estado de Direito como instância mediadora com suficiente poder de persuasão e de força (coerção) para fazer valer o direito de todos a uma vida digna.

O objetivo de realizar interesses particulares no mercado é, por princípio, legítimo. Toda empresa não apenas pode, mas deve, eticamente, defender e proteger seus direi- 
tos. Direitos econômicos, sociais, políticos, culturais. Mas a defesa corporativa desses direitos e interesses está sempre a um passo da pior degeneração que lhe pode ocorrer: a de autocentrar-se, ignorando a comunidade e a sociedade ao redor, ignorando o país, confundindo auferir direitos com levar vantagens (interesses). Isso caracteriza o que se chama corporativismo, a doença ética das empresas. Muitas constituições de países, entre eles o Brasil, definem o princípio do valor e função social da propriedade como precedente ao seu valor e função particular (Artigos 185 e 186).

\section{Ética e moral}

Até aqui parece evidente estarmos nos movendo num plano epistemológico pretensamente crítico, pelo fato de recorrermos a argumentações suficientemente verificáveis à vista dos fatos e evidências históricos e culturais, além de lógicos (com suficiente consistência, coerência, congruência e conseqüência). Mas pode não parecer evidente que estamos também nos movendo num plano ético.

Isso requer esclarecimentos prévios sobre os polêmicos conceitos de ética e moral. Consideremos a moral como referência a particularidades culturais, institucionais e individuais de conduta, e a ética como uma referência ao âmbito da universalidade. A ética será, assim, como uma teoria crítica e uma reflexão criteriosa sobre a conduta moral. A ética busca extrair das diversas experiências morais das diferentes culturas algum conjunto de princípios que possam ser considerados referências comuns a toda a humanidade e, assim, alcançar alguma universalidade. Nesse sentido, por exemplo, a Declaração Universal dos Direitos Humanos, da ONU (1948), aparece como um documento fortemente ético, resultante de um esforço reflexivo consensual, com enorme poder de universalidade.

O raciocínio que fundamenta essa posição é o seguinte: a morada (mos, moris) do homem, como animal social, é sempre alguma cultura particular, algum solo pátrio, alguma língua mátria, uma parte num todo. Os padrões culturais particulares, parciais, regulam as condutas ou comportamentos considerados legítimos por uma determinada sociedade, povo, nação, etnia. Há morais específicas, também, em grupos sociais mais restritos: uma instituição religiosa, um partido político, um grupo de identidade estética, de identidade afetivo-sexual, uma gangue urbana e muitos outros. Há, portanto, muitas e diversas morais. Cada sistema moral cria seus próprios mecanismos particulares de legitimação de condutas. A moral não tem, pois, de partida, compromisso com a universalidade. Só busca alguma universalidade quando atacada, ocasião em que tenta justificar-se construindo explicações com alguma presunção (ideologia) de universalidade. Isso tem duas implicações. A primeira, de que até um certo ponto, dentro de uma certa margem, a diversidade moral deve ser reconhecida como legítima, dada a contingência de só haver vida humana concreta e materialmente dentro de determinadas fronteiras culturais (não existe ser humano abstrato, que não seja cultural). A segunda, de que se impõe a necessidade de juízos críticos universais acerca das limitações da moral, sob pena de se porem em risco os legítimos ideais e aspirações humanas de realização do direito universal. Este segundo aspecto 
é o que fundamenta a emergência necessária do âmbito da ética, como referência em prol da universalidade.

A ética, portanto, não é teoria metafísica e, sim, um conjunto de referências, princípios e disposições voltados para a ação, para balizar as ações humanas entre o supostamente correto e o incorreto, o supostamente bom e o mau, o supostamente justo e o injusto.

Entretanto, habituamo-nos a uma literatura em ética e moral que limitou o âmbito de seu alcance ao dos relacionamentos intersubjetivos, num plano de exclusiva horizontalidade. Trata-se da tradição contratualista, que se consagrou no século XVIII como supostamente a única forma de solução moral e ética para a diversidade de desejos humanos, porque o século XVIII precisava urgentemente resolver os conflitos sociais resultantes de uma economia de mercado crescente que, a permanecer desregulada, resultaria na guerra de todos contra todos. Trata-se, portanto, de uma ética e moral estritamente burguesas.

Antes disso, no medievo ocidental, sabemos como essa regulação se fazia: no plano exclusivamente vertical das relações com o divino, mediadas por uma instituição particular, a Igreja, que se dizia autorizada para tal pelo próprio divino.

Se saltarmos de volta à contemporaneidade, não será difícil percebermos como não é mais possível ignorar a rede complexa de reciprocidades com que a civilização vem nos cercando: estamos implicados em relações públicas (aqui a expressão cabe com todo o seu vigor e em todos os seus sentidos) de convívio social-cultural (intersubjetividades e interculturalidades) e, ao mesmo tempo, de convívio ambiental. Um eixo não é sustentável em si mesmo nem independente do outro. Temos que encontrar formas de convívio sustentável com a natureza (nosso eixo vertical material voltado para o centro do planeta que habitamos e do qual somos parte) e com os outros seres humanos (nosso eixo horizontal, que é infinito, pois se destina não apenas aos outros seres humanos atuais, próximos e remotos na cultura, mas também às gerações futuras). Essas relações todas são públicas no sentido pleno: atingem todos, de todas as formas, em todos os direitos e deveres. A implicação mais evidente dessa obrigação coletiva, supondo nossa posição numa sociedade democrática, é a da transparência de todos os processos.

\section{0 conflito entre transparência e sigilo}

A questão da transparência é delicada e perigosa porque está também intrincada numa complexa rede de reciprocidades. Se supomos que toda ação econômica ou social de qualquer sujeito, individual ou coletivo, implica externalidades, ou seja, afeta de algum modo todas as condições externas, ambientais e socioculturais, e isso se impõe porque é inconcebível um sujeito isolado; e se supomos que todos os sujeitos, individuais e coletivos, têm direito a conhecer tudo o que potencialmente ou efetivamente os afeta, deveremos concluir que a transparência deve ser um princípio requerido de 
toda ação que tenha como destinatário o público. Isso está consagrado na Constituição Brasileira, em seu Artigo 37. Nessa própria definição, porém, já resguardamos um âmbito de privacidade como um direito também fundamental de todo sujeito. Referimo-nos a sujeitos individuais e a sujeitos coletivos. Toda instituição, Governo, Estado, tem, junto com os deveres de transparência/publicidade, direito a um âmbito de privacidade. O fundamento da privacidade é, por um lado, negativo: não existe apenas bondade no mundo e todos têm o direito de proteger sua integridade física e moral contra rivalidades, invejas, conspirações, vinganças. A positividade fundamental do direito à privacidade está relacionada à capacidade de autodeterminação (sempre supostamente bem-intencionada, justa, honesta, responsável e conseqüente) de todo sujeito livre e consciente. Ou seja, a privacidade é componente da honra e da dignidade de todo sujeito (individual ou coletivo).

Se assim é, podemos concluir: a todo direito de transparência do público impõe-se um dever de transparência do sujeito ou da instituição em ação; a todo direito de privacidade do sujeito ou da instituição em ação impõe-se o dever de sigilo do público e de cada sujeito que o constitui.

O sempre potencial conflito entre transparência e sigilo encontra, assim, um critério ético de solução. Em conseqüência, as chamadas relações públicas institucionais voltam a mostrar-se como insoluvelmente problemáticas e ambíguas. E somos devolvidos à obrigação ética de ter que julgar e agir de modo criterioso e responsável diante de todo conflito potencial, aparente, virtual e real, que implique direitos e deveres de transparência e de sigilo.

\section{Ética e valores: intrínsecos e instrumentais}

Há quem pense os valores como entidades com vida própria, uma realidade abstrata. Mas os valores não existem fora da realidade material, fora da prática, fora da ação. Os valores são qualidades dos seres e das suas ações. Podemos pensar os valores em duas classes: valores instrumentais e valores intrínsecos.

Nós olhamos para a natureza com nosso ponto de vista e, centrados em nossos interesses específicos, pensamos que ela esteja aí apenas para nos servir. Esse é o valor instrumental da natureza. Sem dúvida, podemos nos servir dela, e precisamos disso para viver: servimo-nos da força física de animais domésticos para o trabalho e, principalmente, comemos (destruímos) raízes, tubérculos, folhas, talos, frutas, carnes de peixes, aves e animais. Isso é um paradoxo: que a vida dos seres vivos se alimente da morte de outros seres vivos. Mas assim é. A natureza tem um valor instrumental entre si, nas cadeias alimentares, e para nós que estamos no topo da cadeia.

Mas o sistema vida, além desse valor instrumental, tem também um valor intrínseco. A espécie humana atual começou a formar-se neste planeta há cerca de $200 \mathrm{mil}$ anos, e o sistema-vida já estava aí com sua exuberante diversidade há quase 3 bilhões de anos. Não podemos olhar para trás e deixar de pensar que todas as espécies de 
seres vivos que aí estão, ou aí estiveram, têm um valor imenso, intrínseco a elas: elas evoluíram, diferenciaram-se e produziram a espécie humana por si mesmas, por sua energia intrínseca (ou, se se quiser, por uma interferência criacionista sobrenatural: o espanto é o mesmo, o valor intrínseco é o mesmo). Se nossa espécie tem o valor que tem por sua inteligência, o sistema-vida que nos produziu tem o valor maior de nos ter produzido como suas criaturas. Cada reino de seres vivos tem valor intrínseco, é belo e bom em si mesmo: os microrganismos, as plantas, os animais, os humanos.

A sustentabilidade é um sinal de inteligência produtiva se pensamos em manter disponível o valor instrumental da natureza; é um sinal de inteligência ética se pensamos em respeitá-la e preservá-la também por seu valor intrínseco.

Os valores instrumentais são mediações econômicas, mas também políticas, sociais, culturais. As qualidades dos objetos, das ações, dos indivíduos como agentes são a referência de valor. Algo vale quando serve a alguma ação (uso ou troca). Mas a economia de mercado reduziu os valores intrínsecos a valores de uso, e esses a valores de troca entre dinheiro e mercadoria.

Cada pessoa, igualmente, tem o direito e o dever de valorizar-se e ser valorizada. Tem valor intrínseco e valor instrumental. Valor intrínseco como ser vivo e humano que se forma, se faz, se desenvolve, realizando seus talentos, realizando seu bem-estar (felicidade). Esse valor intrínseco poderá ser usufruído pelo próprio indivíduo, assim como poderá ser compartilhado gratuitamente com outro (amizade, amor). Ao mesmo tempo, nada impede eticamente que os valores de um indivíduo sejam postos a serviço instrumental de outro, dentro de condições específicas. É o que se passa na relação de trabalho. Servir como instrumento a outro se justifica quando isso se dá numa relação livre e ética, que gera bens que, em troca, mantêm e desenvolvem a vida do indivíduo. Nessa relação contratual de trabalho, todo indivíduo tem o direito de ser reconhecido e respeitado em seus valores instrumentais, mas também, e principalmente, em seus valores intrínsecos.

\section{Limites do mercado}

A economia de mercado fundamenta-se na possibilidade (teórica) do planejamento perfeito, da concorrência perfeita, da relação perfeita entre mercado e sociedade, e trata todas as imperfeições como disfunções operacionais do grande sistema. Para solucionar, criam-se mecanismos de correção das disfunções e, mais, supõe-se a existência de automatismos nessas correções. Historicamente, acumularam-se razões fortes que negam a possibilidade dessa perfeição e, por conseqüência, afirmam a impossibilidade de solução de todas as disfunções. Ao mesmo tempo, a economia de mercado tem como principal fundamento a competição, e nisso também ela opera uma ambivalência insolúvel. A competição está sempre à beira de dois abismos: de um lado, a destrutividade; do outro lado, a possibilidade de um desenvolvimento saudável favorável a todos. 
Este é o desafio radical na construção de um novo padrão de conduta nas empresas, especialmente em suas relações com todos os seus públicos: que não se perca a noção da sociedade e da humanidade como realidade complexa à qual ela deve uma resposta em termos de desenvolvimento econômico, tecnológico, social, cultural.

No quadro atual de crise ética da humanidade, temos tomado consciência de que esbarramos nos limites da nossa sobrevivência como espécie: encontramo-nos numa rota histórica de autodestruição que precisa ser corrigida. O grande tema é o da sustentabilidade global. Requer-se uma nova ordem internacional, planetária, que inclua equilibradamente o ambiental, o econômico, o político, o social, o cultural. As Nações Unidas e seus diversos órgãos setoriais vêm intensificando os esforços para a construção de uma nova ordem mundial sustentável. Os resultados até aqui ainda não garantem futuro às próximas gerações.

A competitividade se acirrou, e também se tornou mais sutil. $\mathrm{O}$ vale-tudo para vencer não vale mais. Há novos valores no ar, que devem ser considerados. O terceiro setor ganhou força, em conseqüência da minimização do poder do Estado e da privatização das economias. O consumo aumentou seu poder de controle sobre a produção. A mídia não tem como se sustentar sem se ancorar nos novos valores difundidos entre seu público, ou seja, sem propagar também as novas exigências éticas mais críticas que pairam na consciência coletiva da população esclarecida (seus leitores, espectadores, internautas). Políticos não se elegem mais sem ao menos prometer ações de redução da desigualdade social, de inclusão cultural, de justiça, de conduta ética e outras propostas afins.

Na década de 1990, no mundo empresarial, consagrara-se a valorização da ecologia (defesa da biodiversidade). Muitas empresas associaram-se a projetos de preservação do meio ambiente, preocupando-se em demonstrar que seus produtos eram "naturais". Na década atual, um dos temas mais fortes é a valorização da sociodiversidade, dos direitos sociais e culturais, mediante políticas afirmativas, proativas. À primeira vista, isso soa contraditório: é estranho a ética provir do setor (mercado) que historicamente tem sido o maior responsável por seu sacrifício ou eliminação. Considerando-se com atenção, percebe-se que até certo ponto faz sentido esse avanço ético, mesmo que movido por interesses corporativos de sobrevivência no mercado, e não tanto por direitos universais.

O fenômeno é novo: o consumo controla cada vez mais a produção. A força da consciência dos consumidores tem sido reconhecida como elemento decisivo no jogo competitivo do mercado. As empresas com Responsabilidade Social tendem a ser mais produtivas e apresentar maiores índices de crescimento. Busca-se uma nova postura responsável das empresas diante dos problemas ambientais e culturais, locais e globais, para se agregar valor a seus produtos e serviços.

É o investimento na sustentabilidade e perenidade empresarial. Depois do foco sobre reengenharias da administração, qualidade total de produtos e serviços, revalorização das individualidades no processo produtivo (ainda que restritas ao nível gerencial), as empresas exploram esse novo filão no mercado: a Responsabilidade Social, a Ética Empresarial. 


\section{Ética nas Relações Públicas e sustentabilidade}

Muitas empresas trataram inicialmente o tema da ética estritamente em termos de mercado: investir mercadologicamente na ética. Parecia a elas que o departamento de marketing bastaria para cuidar de tudo: desenhar programas de apoio a projetos sociais da comunidade, associar-se a projetos de proteção ambiental, redigir um Código de Ética Empresarial. Na seqüência, os setores de Relações Públicas foram convocados a operar esse tipo de redução no trato com os diversos públicos. Fizeram da Responsabilidade Social e do Código de Ética uma peça publicitária. Reduziram a ética a uma etiqueta (no duplo sentido: de "etiquinha", ou seja, redução da ética a um valor agregável a mercadorias; e no sentido de rótulo ou selo: a etiqueta da grife empresarial).

Outras empresas foram apercebendo-se de que havia um outro desafio. Levantou-se a hipótese de que o mercado (assim como a política) estivesse esbarrando num limite de sustentabilidade que requereria um outro tipo de atitude diante das questões ambientais, sociais, éticas. Passaram a ensaiar um investimento propriamente ético na ética. Isso significaria apostar num novo padrão de relação com todos os stakeholders, num compromisso efetivo com a sociedade, a cultura, a comunidade local, o meio ambiente, a vida dos colaboradores da empresa, sem inviabilizarem seus negócios. Essas empresas são as que olham mais à frente, para uma necessária, ainda que precária, reconciliação entre economia e sociedade, produtividade e desenvolvimento, lucro e justiça social, empreendedorismo e ética. Apostam na perenidade da empresa e da sociedade. Mobilizam suas Relações Públicas nesse sentido de comunicação e de compromisso público.

O tema já vinha impondo-se há mais de uma década, mas não há dúvida de que um acontecimento concreto disparou e consagrou a ética empresarial em todo o mundo, impondo um padrão de conduta ética rigorosa nas Relações Públicas: em 2001, a descoberta de uma série de fraudes corporativas nas empresas norte-americanas WorldCom, Enron, Arthur Andersen e outras abalou seriamente a confiança dos investidores norte-americanos (largamente habituados a negociar em bolsa de valores) e derrubou subitamente as cotações nas principais bolsas de valores do mundo. As fraudes deixaram de ser um problema local e tornaram-se uma ameaça grave ao equilíbrio do mercado. Rapidamente, em janeiro de 2002, o congresso dos EUA aprovou uma rigorosa lei (formulada e defendida por Paul Sarbanes e Michael Oxley), que foi sancionada pelo Presidente G. W. Bush em 30 de julho de 2002.

A Lei Sarbanes-Oxley tornou-se um marco histórico: exige transparência nas relações públicas, na contabilidade e auditorias das empresas, em proteção aos consumidores e acionistas. Essa cultura da correção e transparência se difundiu, com extraordinário poder de disseminação, pelas cadeias produtivas. Cabe não subestimar o fato de que esses procedimentos politicamente corretos têm limites éticos. Mas não há dúvida de que, com relação à ordem anterior, representam um avanço. 
A lição de 2001-2002 nos EUA foi a de que o mercado não tem nenhuma "mão invisível" que automaticamente faria com que o conjunto dos interesses individuais e institucionais se converta em interesses de toda a sociedade, como pensava o economista Adam Smith nos fins do século XVIII. O mercado requer alguma regulação e cabe ao Estado realizar isso em nome do bem comum, ou seja, para o direito de todos.

Deve-se considerar também que a ciência e a arte da gestão empresarial contemporânea vêm esbarrando em limites de desenvolvimento lógico de sistemas funcionais em busca de máxima eficiência e produtividade das organizações. No limite do desenvolvimento funcional desses processos, vem-se vislumbrando o novo horizonte: a capacidade de desenvolvimento ilimitado das pessoas. A convicção já se difundiu: mais do que novos processos sistêmicos, é o desenvolvimento das pessoas dentro das empresas que pode fazer toda a diferença. Esse ponto toca diretamente também o campo das Relações Públicas.

Uma nova política empresarial nessa direção começa a se formular, na busca de sustentabilidade e perenidade para seus empreendimentos. Ao mesmo tempo, ela pode permitir uma adequação mais justa das empresas aos compromissos da sociedade brasileira e ao concerto das Nações Unidas, na construção de um novo modo de desenvolvimento sustentável, nos aspectos ambiental, econômico, social, político, cultural.

\section{Referências}

BOBBIO, Norberto. A era dos direitos. São Paulo: Campus, 1997.

BOFF, Leonardo. Saber cuidar: ética do humano. Petrópolis: Vozes, 1999.

CASALI, Alípio. Por um código de ética para os agentes públicos e lideranças políticas, sociais e comunitárias. São Paulo: Fundação Prefeito Faria Lima/Cepam, 2000.

CHAUÍ, Marilena. Convite à filosofia. São Paulo: Ática, 1999.

COSTA, Jurandir F. A ética e o espelho da cultura. Rio: Rocco, 1994.

DUPAS, Gilberto. Ética e poder na sociedade da informação. São Paulo: Unesp, 2000.

DUSSEL, Enrique. Ética da libertação na idade da globalização e da exclusão. Petrópolis: Vozes, 2000.

FERRELL, O. C.; FRAEDRICH, John; FERRELL, Linda. Ética empresarial: dilemas, tomadas de decisões e casos. Rio de Janeiro: Reichmann \& Affonso Eds., 2001.

FICHER, Rosa Maria. 0 desafio da colaboração - prática de responsabilidade social entre empresas e terceiro setor. São Paulo: Ed. Gente, 2002.

FREUD, Sigmund (1929). 0 mal-estar na civilização. Rio: Imago, 1997.

GORE, Al. Uma verdade inconveniente. Barueri, SP: Manole, 2006.

HABERMAS, Jürgen. Consciência moral e agir comunicativo. Rio de Janeiro: Tempo Brasileiro, 1989.

INSTITUTO ETHOS. Publicações. Disponível em: www.ethos.org.br/publicações

JONAS, Hans. 0 princípio responsabilidade: ensaio de uma ética para a civilização tecnológica. Rio de Janeiro: Contraponto: Ed. PUC-Rio, 2006.

KANT, Immanuel. Fundamentação da metafísica dos costumes. São Paulo: Ed. Victor Civita, 1974. Col. "Os Pensadores”, vol. XXV. KOHLBERG, Lawrence. Essays in moral development. San Francisco: Harper and Row, 1987.

LIGHT, Andrew e ROLSTON III, Holmes (eds.). Environmental ethics. Malden: Blackwell, 2003.

NOVAES, Adauto (org.). Ética. São Paulo: Cia. das Letras / Secretaria Municipal de Cultura, 1992.

SANDRONI, Paulo. Dicionário de economia do século XXI. São Paulo/Rio: Ed. Record, 2005.

VÁZOUEZ, Adolfo S. Ética. Rio de Janeiro: Civilização Brasileira, 1999.

WHITAKER, Maria do Carmo. Ética na vida das empresas - depoimentos e experiências. São Paulo: DVS, 2007. 